\title{
Functional Residual Capacity in Normal Neonates and Children up to 5 Years of Age Determined by a $\mathbf{N}_{2}$ Washout Method
}

\author{
TILO GERHARDT, LINDA REIFENBERG, DOROTHY HEHRE, ROSALYN FELLER, AND \\ EDUARDO BANCALARI
}

Department of Pediatrics, Division of Neonatology, University of Miami School of Medicine, Miami, Florida 33101

\begin{abstract}
Functional residual capacity (FRC) was determined in 50 infants by a simplified $\mathrm{N}_{2}$ washout method. Fourteen infants were preterm, four full-term newborns and the rest were 1 month to $5 \mathrm{yr}$ of age. Weight ranged from 1.19 to $25.8 \mathrm{~kg}$. The method gave well reproducible values with a mean coefficient of variation of $3.9 \%$. The FRC values are equally well correlated to weight and length $(r=0.98)$. The correlation with weight is linear, intercepting the $x$ axis $(F R C=0)$ at a weight of $480 \mathrm{~g}$, the one with length is best described by a power curve. The course of the regression lines reflects the observation that FRC per $\mathrm{kg}$ weight or per $\mathrm{cm}$ length is lower in neonates than in larger infants. The FRC measurements are in the same range as values obtained by other investigators using the $\mathrm{N}_{2}$ washout or He-dilution techniques. The values are significantly smaller than thoracic gas volume measurements obtained by plethysmography. This difference may be due to air trapping or to possible methodological problems with the plethysmographic technique. The data demonstrate that FRC can be measured easily and accurately in preterm and older infants using a $\mathrm{N}_{2}$ washout technique. (Pediatr Res 20: 668-671, 1986)
\end{abstract}

\section{Abbreviations}

FRC, functional residual capacity

TGV, thoracic gas volume

The measurement of FRC is an important component when evaluating pulmonary function in neonates and infants. FRC needs to be known as reference value when comparing compliance and conductance of individuals with different size and its increase with age provides important information about lung growth and development.

Most of the lung volume determinations in neonates and infants have been done by plethysmography measuring TGV rather than the FRC. This technique is difficult to apply to sick or small preterm infants, requires complicated highly sensitive equipment, and bears a high risk of technical error. Airway closure at FRC as may occur in the newborn infant and uneven distribution of pleural pressure may also lead to erroneous results

Received January 6, 1986; accepted March 11, 1986.

Address correspondence to Tilo Gerhardt, M.D., Department of Pediatrics (R131), University of Miami School of Medicine, P.O. Box 016960, Miami, FL 33101

Supported in part by the National Institutes of Health, Grant 5R01-HL2502304, The State of Florida, Department of Health \& Rehabilitative Services, Children's Medical Service and University of Miami/Project: New Born.
(1). This explains the large variability of results obtained with this method.

More recently the He-dilution method has been scaled down and perfected for the use in infants (2) and the classical $\mathrm{N}_{2}$ washout technique has been computerized to allow breath by breath analysis of $\mathrm{N}_{2}$ washed out $(3,4)$. We have developed a simpler, open circuit $\mathrm{N}_{2}$ washout technique suitable to measure FRC in small animals and neonates (5).

FRC or TGV measurements have been reported most frequently in term neonates or infants with respiratory illness (612). Only a few of these studies include preterm infants $(7,11$, 12 ), and none of them has been done with the $N_{2}$ washout method.

In the present study FRC measurements were performed in normal infants including preterm and term neonates and infants up to $5 \mathrm{yr}$ of age using the open circuit $\mathrm{N}_{2}$ washout technique (5).

\section{MATERIALS AND METHODS}

Fifty healthy infants, free of any signs of pulmonary disease or upper respiratory infection were studied. Their weight ranged from 1.19 to $25.8 \mathrm{~kg}$, and their age from $1 \mathrm{wk}$ to $5 \mathrm{yr}$. Eighteen infants were studied during the newborn period (first 28 days after birth). Their gestational age ranged from $32 \mathrm{wk}$ to term, 14 infants were preterm. Gestational age was determined by Dubowitz examination, and added to postnatal age to obtain postconceptional age. None of the infants had a history of respiratory disease or a need for mechanical ventilation. All were breathing room air.

Newborn infants were studied without sedation while all older infants were sedated with $50 \mathrm{mg} / \mathrm{kg}$ chloralhydrate po. The study was done during sleep while infants rested in the supine position. The procedure was well tolerated. There were no unsuccessful attempts and arousal during the measurement occurred in only one of 10 infants.

The details of the system used to measure FRC were described previously (5). Briefly it consists of a blender connected to a source of oxygen and helium, providing a stable continuous flow of any helium/oxygen mixture. The gas is warmed and humidified and passed through a breathing circuit. The infants breathe the gas from the circuit through a $\mathrm{T}$ tube. The gas leaving the circuit is mixed in a mixing chamber placed at the end of the system. The $\mathrm{N}_{2}$ concentration of the gas leaving this chamber is analyzed with a mass spectrometer and the signal is integrated electronically avoiding the necessity of gas collection. The amount of $\mathrm{N}_{2}$ washed out from the infant's lungs is proportional to the integrated $\mathrm{N}_{2}$ concentration as long as the flow through the circuit is stable. Gas flow is adjusted to the estimated peak inspiratory flow of the infant to prevent rebreathing. Calibration 
is done by attaching a $50-\mathrm{ml}$ syringe filled with air to the $\mathrm{T}$ tube and by washing this gas slowly into the circuit. The signal of the integrated $\mathrm{N}_{2}$ concentration equals $39 \mathrm{ml}$ of $\mathrm{N}_{2}\left(78 \% \mathrm{~N}_{2}\right.$ in air).

The infants breathed from the circuit through nasal prongs (deadspace 0.5-1.0 ml) connected to the nares at end of expiration. Washout was continued for approximately 2 min until alveolar $\mathrm{N}_{2}$ had dropped to 3-6 $\mathrm{mm} \mathrm{Hg}$, indicating that most of the $\mathrm{N}_{2}$ in the lungs had been washed out. The initial alveolar $\mathrm{N}_{2}$ concentration was measured in 10 infants of different age and found to be $79 \%$. This concentration was used as standard value in the FRC calculation for all infants. All measurements were repeated at least three times. No corrections were made for $\mathrm{N}_{2}$ washed out from blood and tissues. Functional residual capacity was calculated from the total amount of $\mathrm{N}_{2}$ washed out and the alveolar $\mathrm{N}_{2}$ concentration before and at the end of the washout. Values were corrected for BTPS.

To determine reproducibility of the measurements means \pm $\mathrm{SD}$ and coefficients of variation were calculated for the three FRC determinations in each patient. Linear regression analysis was employed to test the correlation between the first and second FRC measurement and its $95 \%$ confidence limits.

To depict the change in FRC with growth, regression analysis between FRC as dependent variable and weight, length, and age as independent variables was performed and the $95 \%$ confidence limits for the regression lines were calculated.

The study was approved by the committee for protection of human subjects at the University of Miami, and informed consent was given by the parents of each infant studied. The infants studied were siblings or cousins of children enrolled in a followup study of chronic lung disease or the children of hospital personnel familiar with the test procedures.

\section{RESULTS}

The mean coefficient of variation of the three FRC determinations was $3.9 \%$ varying from 0.2 to $9.0 \%$.

There was no significant difference between the first and second measurement $(p=0.87)$ and the correlation coefficient between the two determinations was 0.99 . The slope of the regression line was close to $1.0(0.986)$ and the intercept with the $y$ axis close to zero (1.7). The $95 \%$ confidence limits for an individual second determination ranged from 91.3 to $109.3 \mathrm{ml}$ if the first measurement was $100 \mathrm{ml}$.

The values of FRC were closely correlated with weight. The regression lines for males and females did not show significant differences and therefore the values for both groups were analyzed together. The slope of the regression line was $20.0 \mathrm{ml} / \mathrm{kg}$ and its intercept with the $\mathrm{x}$ axis $0.480 \mathrm{~kg}$. The correlation coefficient was 0.98 .

Each of the 14 preterm infants had FRC values above the regression line, $10-35 \%$ higher than the estimate for their weight. The contribution of these values to the regression line resulted in a decrease in slope and a shift of the intercept with the $x$ axis to the left. If these infants are excluded from the analysis, the regression line has a slope of $20.4 \mathrm{ml} / \mathrm{kg}$ and the intercept with the $\mathrm{x}$ axis occurs at $0.725 \mathrm{~kg}$ weight (Fig. 1).

The correlation of FRC with weight for the preterm infants showed a similar slope (20.7) as in the rest of the infants; however, the regression line was shifted to the left (intercept with $\mathrm{x}$ axis $0.304 \mathrm{~kg}$ ) (Fig. 2). The regression coefficient for both subgroups was also 0.98 .

The changes in FRC with growth were also closely related to length. This was not a linear correlation but best fit was achieved with a power curve. Again there was no difference between the curves for male and female infants so that all measurements were analyzed together. The results are shown in Figure 3. The correlation coefficient was 0.98 , and FRC was related to length as follows: FRC $=0.000937 \mathrm{x}^{2.78}$, where $\mathrm{x}$ is length in $\mathrm{cm}$.

FRC also showed a close correlation with postconceptional age $(r=0.98)$. Best fit was reached with a logarithmic correlation

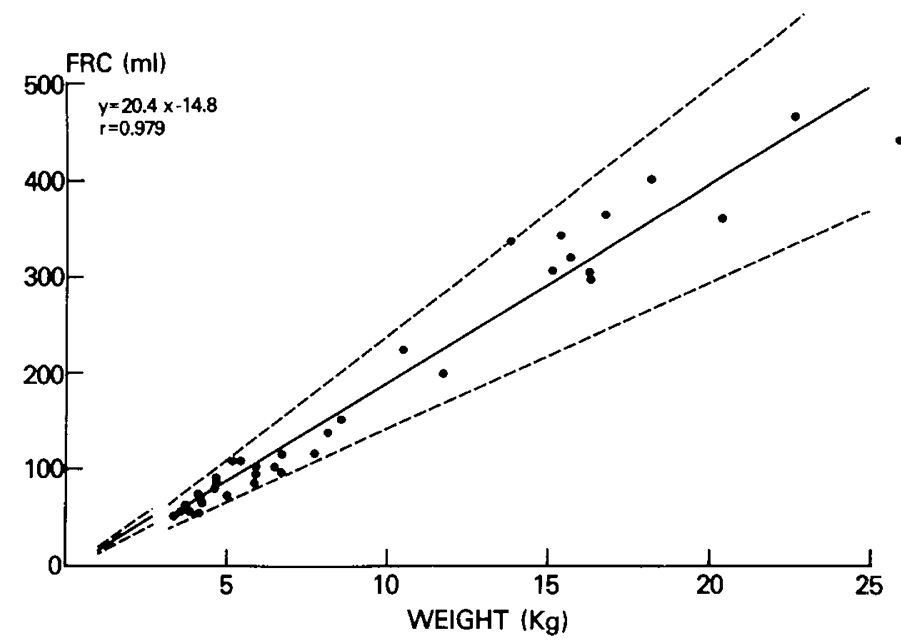

Fig. 1. Correlation between FRC and weight for infants $3.0-25.0 \mathrm{~kg}$ in weight; $n=36$. The dotted lines indicate the $95 \%$ confidence limits for individual values. It is evident that values for infants $1-3 \mathrm{~kg}$ in weight (shown in more detail in Fig. 2) are shifted to the left.

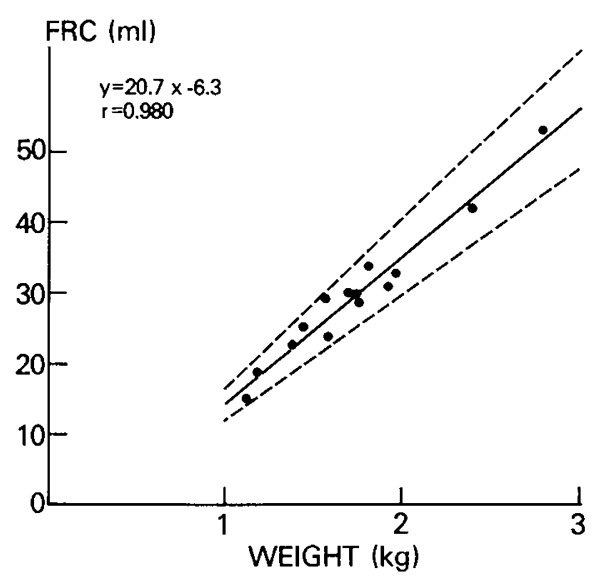

Fig. 2. Correlation between the FRC and weight for infants $1-3 \mathrm{~kg}$ in weight; $n=14$. The dotted lines indicate the $95 \%$ confidence limits for individual values.

and the regression line had a steep initial increase up to 15 months postconceptional age and then flattened (Fig. 4). The equation was: $\mathrm{FRC}=176 \ln \mathrm{x}-334$, where $\mathrm{x}$ is postconceptual age in months. (note $\ln \mathrm{x}$ is the natural logarithm of $\mathrm{x}$.)

The ratios FRC/weight, FRC/length, and FRC/age were lower in the neonatal period than in older infants.

\section{DISCUSSION}

The method used in this study to measure FRC was previously found to give accurate and reproducible results in vitro and in small animals (5). The present study confirms the feasibility and reproducibility of the method in human infants. The mean coefficient of variation of the three measurements of FRC in each patient was only $3.9 \%$, smaller than in most studies using plethysmographic methods or He-dilution. The correlation between first and second FRC determination was excellent with the $95 \%$ confidence limits very close to the regression line.

The method is easy to use, can be repeated at short time intervals, and does not require complicated equipment. The possibility for technical errors is minimal, and the calibration and calculation of results is fast and simple. The infants tolerate the procedure well, do not need to be confined to a body box, 
and are not exposed to the risks of hyperoxia, hypoxia, or hypercapnea as with some of the rebreathing methods. The procedure is done in the incubator avoiding the risks of hypothermia.

The method measures only gas in communication with the airways and does not include trapped gas. Areas of hypoventilation as may be present in infants with lung disease can be measured by prolonging the washout time beyond $2 \mathrm{~min}$.

The FRC measurements showed good correlation with body weight and length. The fact that correlation with length was not linear is not surprising and has been observed before (10). While length increases linearly, lung volume increase in three dimensions. Most pulmonary laboratories have used length as reference value for FRC because length is less influenced by abnormal nutritional states than weight. This situation is illustrated by the underestimation of FRC in infants with low birth weight when

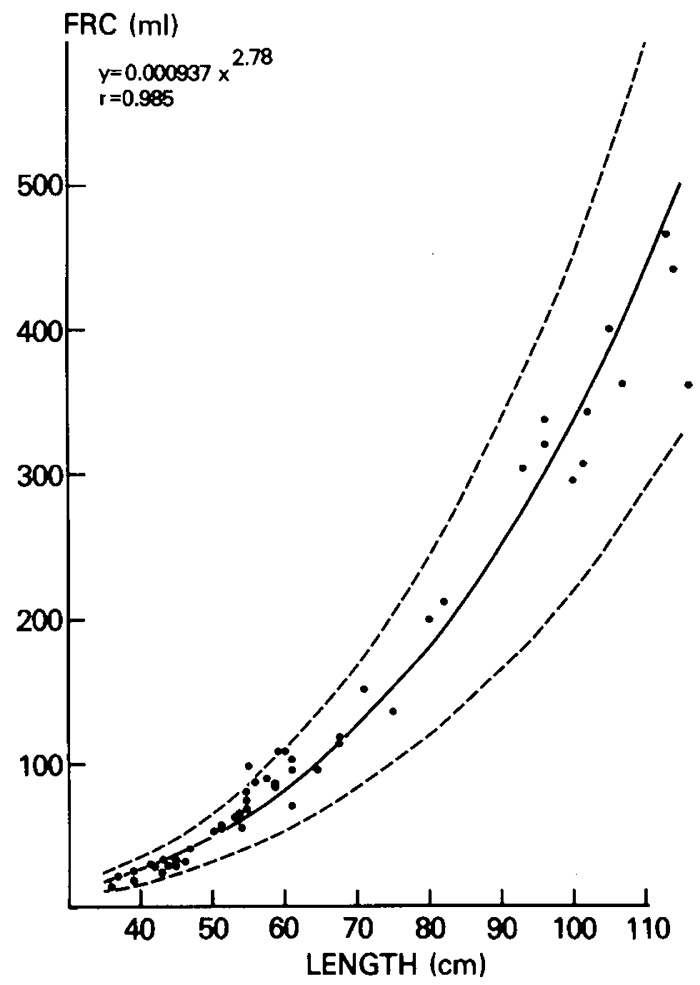

Fig. 3. Correlation between the FRC and length for all infants; $n=$ 50. The dotted lines indicate the $95 \%$ confidence limits for individual values. using the regression line that includes all 50 infants. Because the preterm infants have less subcutaneous fat and lose more weight after birth, all their FRC values fall above the regression line (Fig. 1). The regression line of FRC for weight intercepts the $\mathrm{x}$ axis at a body weight of $480 \mathrm{~g}$ corresponding to a gestational age of $20-22 \mathrm{wk}$. This is just prior to the time when air spaces begin to form and lung volume starts to increase rapidly (12).

The correlation between FRC and age reflects the increase in FRC with growth. It is close in a population with normal growth curves for weight and length but will be altered in conditions with abnormal growth pattern. The FRC values from the low birth weight infants shifted the initial part of the curve to the right because after birth their age increases without increases in weight or FRC until they receive sufficient calories. This weight shift is illustrated by the intercept of the regression line with the $\mathrm{x}$ axis at $27 \mathrm{wk}$ instead of 23 to $26 \mathrm{wk}$ (12) and the steep initial rise of the curve. This rise is due to higher FRC values of full term infants and lower values of preterm infants who are already $2-3$ wk old, all located within the narrow $8-10$ months postconceptual age range.

The lower FRC/weight, FRC/length, FRC/postconceptual age ratios in smaller as compared to larger infants are reflected by the course of the regression lines which do not intersect the $x$

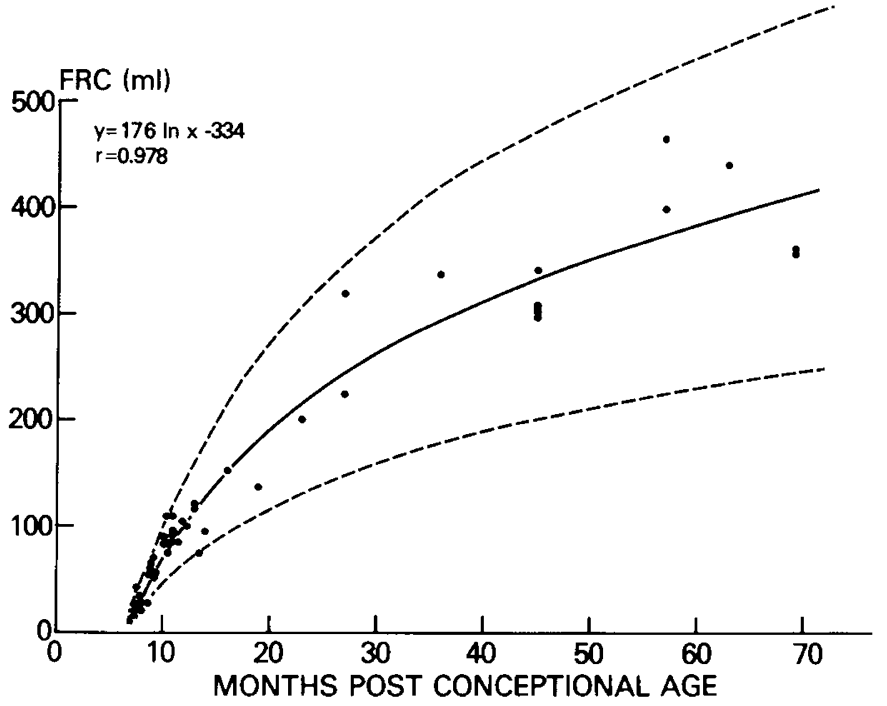

Fig. 4. Correlation between FRC and postconceptional age for all infants. The dotted line indicates the $95 \%$ confidence limits for individual values.

Table 1. Comparison of FRC values at different wt and lengths-previously published measurements and values from present study*

\begin{tabular}{|c|c|c|c|c|c|c|c|c|}
\hline \multirow[b]{2}{*}{ References } & \multirow[b]{2}{*}{ Age range } & & \multicolumn{2}{|c|}{$\mathrm{ml} / \mathrm{kg}$ at } & \multicolumn{2}{|c|}{$\mathrm{ml} / \mathrm{cm}$ at } & \multirow{2}{*}{$\begin{array}{c}\text { Regression to } \\
\text { length }(\mathrm{cm})\end{array}$} & \multirow{2}{*}{$\begin{array}{c}\text { Regression to } \\
\text { wt }(\mathrm{kg})\end{array}$} \\
\hline & & & $3.5 \mathrm{~kg}$ & $10 \mathrm{~kg}$ & $50 \mathrm{~cm}$ & $100 \mathrm{~cm}$ & & \\
\hline Doershuk et al. (6) & $1 \mathrm{mo}-5 \mathrm{yr}$ & $\mathrm{TGV}(\mathrm{pl})$ & 24.4 & 32.1 & 1.99 & 4.70 & $0.0157 \mathrm{x}^{2.238}$ & $36.3 x-41.8$ \\
\hline Stocks et al. (7) & Preterm-1 yr & $\mathrm{TGV}(\mathrm{pl})$ & 33.9 & 31.6 & 2.22 & 4.50 & $6.78 x-228$ & $30.4 x+12.4$ \\
\hline Lacourt et al. (12) & Preterm-term & $\mathrm{TGV}(\mathrm{pl})$ & 29.2 & & & & & $26.1 x+10.9$ \\
\hline Radford (8) & Term-10 mo & $\mathrm{TGV}(\mathrm{pl})$ & 33.5 & 36.7 & & & & $38.4 x-17.3$ \\
\hline Phelan and Williams (9) & Term-10 mo & TGV (pl) & 33.2 & 28.1 & 1.08 & 6.4 & $0.000617 x^{3}+27$ & $25.4 x+27.2$ \\
\hline Cook et al. (10) & Term-adult & $\mathrm{FRC}(\mathrm{He})$ & & & 1.65 & 5.98 & $0.00114 \mathrm{x}^{2.86}$ & \\
\hline Bryan et al. (11) & Preterm-1 yr & $\mathrm{FRC}(\mathrm{He})$ & & & 1.48 & 3.43 & $5.378 x-194.73$ & \\
\hline Taussig et al. (2) & $3 \mathrm{mo}-3 \mathrm{yr}$ & $\mathrm{FRC}(\mathrm{He})$ & 15.2 & 23.7 & 0.79 & 4.26 & $7.74 x-347.717$ & \\
\hline Ronchetti et al. (17) & Preterm & $\mathrm{FRC}(\mathrm{He})$ & 20.5 & & & & & \\
\hline Sjöqvist et al. (4) & Term & $\operatorname{FRC}\left(\mathrm{N}_{2}\right)$ & 19.8 & & & & & \\
\hline Kraus and Auld (13) & Preterm & $\mathrm{FRC}(\mathrm{He})$ & 28.3 & & 1.2 & & & \\
\hline Nelson et al. (14) & Preterm-term & $\operatorname{FRC}\left(\mathrm{N}_{2}\right)$ & 31.3 & & & & & \\
\hline Hanson and Shinozaki (3) & Preterm-term & $\operatorname{FRC}\left(\mathrm{N}_{2}\right)$ & 17.7 & & & & & \\
\hline Present study & Preterm-5 yr & $\operatorname{FRC}\left(\mathrm{N}_{2}\right)$ & 16.2 & 18.9 & 1.0 & 3.4 & $0.000937 \mathrm{x}^{2.78}$ & $20.0 x-9.6$ \\
\hline
\end{tabular}

* pl, plethysmography; $\mathrm{He}$, helium dilution; $\mathrm{N}_{2}$, nitrogen washout. 
axis at zero but in the positive range or show an exponential increase.

The FRC values related to weight or length are lower than some of the previously published figures for neonates and infants $(6-10,12-14)$ but most of these data were TGV obtained by plethysmography (Table 1). Larger values for TGV than for FRC measured by He-dilution or $\mathrm{N}_{2}$ washout have been noted before and attributed to gas trapping (13-15). It is also possible that the observed difference may be due to methodological problems with the plethysmographic method which overestimates TGV if airway closure at FRC or uneven distribution of pleural pressure occurs (1). Both of these situations are likely to be present in small infants with a relatively low FRC and a highly compliant chest wall.

Another reason for the lower FRC values reported herein may be the supine position of the infant during the FRC measurement. Some studies in older infants have been done in the sitting position which may increase the FRC by $20-30 \%$ (16).

The FRC/weight and FRC/length values for neonates and older infants presented in this study are similar to results obtained by several investigators using the He-dilution or $\mathrm{N}_{2}$ washout techniques (Table 1).

Table 1 allows comparison of values presented herein with previously published values and regressions of FRC for weight and length. Values are given for neonates and older infants. Especially the measurements made by Hanson and Shinozaki (3), Sjöqvist et al. (4), and Ronchetti et al. (17) in neonates and the results obtained by Taussig et al. (2) and Bryan et al. (11) in infants of different age are in the same range as the FRC values of the present study.

\section{REFERENCES}

1. Beardsmore CS, Stocks J, Silverman M 1982 Problems in measurements of thoracic gas volume in infancy. J Appl Physiol 52:995-999
2. Taussig LM, Harris TR, Lebowitz MD 1977 Lung function in infants and young children: functional residual capacity, tidal volume, respiratory rate. Am Rev Respir Dis 116:233-239

3. Hanson JS, Shinozaki T 1970 Hybrid computer studies of ventilatory distribution and lung volume 1. Normal Newborn Infants. Pediatrics 56:900-914

4. Sjöqvist BA, Sandberg K, Hjalmarson O, Ollson T 1984 Calculation of lung volume in newborn infants by means of a computer assisted nitrogen washout method. Pediatr Res 18:1160-1164

5. Gerhardt T, Hehre D, Bancalari E, Watson H 1985 A simple method for measuring functional residual capacity by $\mathrm{N}_{2}$ washout in small animals and newborn infants. Pediatr Res 19:1165-1169

6. Doershuk CF, Downs TD, Mathews LW, Lough MD 1970 A method for ventilatory measurements in subjects 1 months-5 years of age: Normal results and observations in disease. Pediat Res 4:165-174

7. Stocks J, Godfrey S 1977 Specific airway conductance in relation to postconceptional age during infancy. J Appl Physiol 43:144-154

8. Radford M 1974 Measurement of airway resistance and thoracic gas volume in infancy. Arch Dis Child 49:611-615

9. Phelan PD, Williams HE 1969 Ventilatory studies in healthy infants. Pediatr Res 3:425-432

10. Cook CD Helliesen PJ, Agathon S 1958 Relation between mechanics of respiration lung size and body size from birth to young adulthood. $\mathbf{J}$ Appl Physiol 13:349-352

11. Bryan MH, Hardie MJ, Reilly BJ, Swyer PR 1973 Pulmonary function studies during the first year of life in infants recovering from the respiratory distress syndrome. Pediatrics 52:169-178

12. Lacourt G, Polgar G 1974 Development of pulmonary function in late gestation: the functional residual capacity of the lung in premature children. Act Paediatr Scand 63:81-88

13. Krauss AN, Auld PAM 1971 Pulmonary gas trapping in premature infants. Pediatr Res 5:10-16

14. Nelson NM, Prod'hom LS, Cherry RB, Lipsitz PJ, Smith CA 1963 Pulmonary function in the newborn infant: V. trapped gas in the normal infant's lung. $\mathrm{J}$ Clin Invest 42:1850-1857

15. Boon AW, Ward-McQuaid JMC, Milner AD, Hopkin IE 1981 Thoracic gas volume, helium functional residual capacity and air trapping in the first 6 hours of life: The effect of oxygen administration. Early Human Dev 5:157166

16. Geubelle F, Goffin C 1962 Respiratory studies in children. IV. Lung volume and body position in healthy children. Acta Paediatr Scand 51:255-260

17. Ronchetti R, Senterre J, Geubelle F 1971 Functional residual capacity and distribution of the inspired air in the premature baby: preliminary results. Acta Paediatr Belg 25:5-16 